\title{
The Puzzle Of Internationalization: An Experiential Exercise In Strategic International Human Resources
}

Monika Renard, Florida Gulf Coast University, USA

Karen Eastwood, Florida Gulf Coast University, USA

\begin{abstract}
As an increasing number of organizations engage in the process of internationalization, there is a growing need to educate managers and future managers on the strategic decisions involved in going international, and the resultant impact on human resource management practices. This experiential exercise for students in international management classes demonstrates three major issues in the evolution of the multinational enterprise: geographic scope, choices for entry, and global mindset. In addition, human resource issues facing companies in each phase of globalization are highlighted.
\end{abstract}

\section{INTRODUCTION}

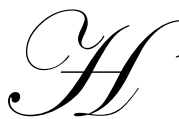

uman Resource (HR) managers are expected to provide key advice to organizational decision-makers on an ever-widening variety of strategic decisions. An important strategic decision facing an increasing number of firms, and therefore one with which HR managers must be knowledgeable, is the decision to "go international." One decision that organizations face in this endeavor is determining the organizational design and structure for the successful conduct of their international business. This decision involves choosing the forms, understanding the stages of development, and implementing the strategy through each functional level of the organization, including HR management. To support and advise on the firm's strategic direction, HR managers must understand the organizational design issues that firms face, the evolving phases in the development of the firm as it grows internationally, and the most common methods of implementing human resource strategy within those designs and phases (Briscoe \& Schuler, 2004). Further, HR activities such as training, rewards, recognition, and career opportunities are essential, especially for international success (Bradford, 2007; Murphy, 2002).

Students in classes in international business, management, and human resources as future general and HR managers, will benefit from understanding and experiencing important aspects of internationalization (Punnett, 2005). Yet, as we help students learn about strategic international human resource management, we must recognize the difficulty that many students have in understanding the complex relationship between strategy and structure in general, let alone in an international context. Internationalization and the strategy-structure relationship are topics that students rarely experience first-hand, so are less meaningful, and therefore more difficult to relate to and to learn. Further, though experiential exercises have been found to be valuable in enhancing learning, there are a few that touch on the concepts of strategic structure (Burgi, Victor \& Lentz, 2004; Harvey \& Morouney, 1998; Joshi, Davis, Kathuria, \& Weidner, 2005: Lyons \& Nicol, 2001; Miller, 2007), and a few that deal with international management (Blanton \& Barbuto, 2005; Ledman, 2001; Oddou, 2005; McDonald, 2001; Punnett, 2005). We could find none that focus on the connection between strategy and structure in the international arena. Therefore, we developed such an exercise to allow students to experience the internationalization process and the phases that organizations go through as they expand, along with the strategic human resource issues that are faced as the firm becomes more global. 


\section{THE EXERCISE: THE PUZZLE OF INTERNATIONALIZATION}

From their textbooks and lectures, students should already be familiar with the developmental stages (or phases) of internationalization. Instructors will want to use the language of their text when reviewing the rules and debriefing this exercise. The "Puzzle of Internationalization" exercise involves groups of students who form "homecountry" firms. Each group is in a different country and represents a unique firm in the early phase of "going international." Each home-country firm begins by trying to complete its task on its own using the natural resources found in its country (puzzle pieces), but soon finds that firm success requires trading its resources and manufactured goods with "foreign" firms (other groups in the class) and thus becoming international.

In each of three rounds of play, the firms experience one of three phases of internationalization identified for this exercise: entry, divisionalization, and internationalization. In each phase the rules for how "home-country" and "foreign" firms can interact are changed to illustrate the changing relationship that comes with evolving strategy and structure in the international context.

The business task of each firm is to complete its chosen jigsaw puzzle by locating and assembling the puzzle from pieces that are distributed widely amongst all the different teams - theirs (home country) and other teams (foreign). To trade for their needed pieces, firms use established value-added trade-prices that demonstrate and take advantage of the value added by assembly of those pieces. The rules also implement the differing firm structure and mindset necessary in each phase of internationalization. Finally, the discussion underscores the message of the exercise and points out the HR implications.

\section{Goals}

The goals of the exercise are to illustrate the need for international trade, to highlight the importance of value-added, to demonstrate phases that occur in internationalization, to demonstrate how structure of the firm may changes with such phases, and to have students experience a few of the complexities of internationalization in a microcosm. The exercise also sets the stage to discuss global mind-sets and HR activities necessary in each phase of internationalization.

\section{Participants}

Students in a wide variety of classes: international strategic human resource management, international management business, or international management, especially, will benefit from the exercise. In addition, students in more basic classes in strategy and management may benefit from the overview it provides of the internationalization process.

The fewest number of people required for the exercise would be nine--three groups of three people. Optimum would be four to five groups of up to six people each. To use the exercise in larger classes, the class could be divided into multiple sections of three to five groups in each section.

\section{Time Required}

The exercise is designed to be completed in one class period of 75 minutes, including the activity and the discussion/debrief. Depending on the speed with which the students complete their puzzles, though, the discussion of the activity may have to take place during the next class period.

\section{Materials}

One 100-piece jigsaw puzzle for each group plus one additional puzzle are needed. Each group will choose one puzzle to complete during Rounds 1-3. The remaining puzzle will be assembled by an "International Joint Venture" (IJV) formed later during Round 3. Puzzles larger than 100 pieces cannot generally be completed in one class period, and so are not recommended. Though many toy departments have these small puzzles, it is also 
possible to customize puzzles for the class. For example, the instructor could Google colorful, interesting images, perhaps of international sights, and print them out on heavier, photo paper. It is best to choose the pictures so that each puzzle has a different color scheme or is otherwise differentiated, to make the puzzle task easier to accomplish in the time allotted. Then the pictures could be stacked and cut into pieces so that each group would have the same number of pieces in its puzzle when assembled. If this approach is taken, then each group of students should also be given a roll of scotch tape to hold together the completed puzzle pieces.

The boxtops showing the completed puzzles or copies of the pictures used as puzzles should be placed together in a neutral location where all of the groups can go to see them.

Each group needs a flat surface on which to assemble its puzzle (a student desk works fine) and a puzzle box-bottom or other container to hold their mixture of puzzle pieces before assembly.

In addition, each country should be given a sheet showing the information in Table 1, or that information should be placed on the board or overhead, so that members of the home country and any foreign representatives who visit their country may see it. (See Table 1).

Table 1-Value-Added Trade-Prices

"Raw materials," or resources (single, unconnected pieces), may be traded for value-added "manufactured goods" (connected pieces) or for other raw materials. The prices that raw materials and manufactured goods trade for are:

- 1 single puzzle piece $=1$ single puzzle piece

- $\quad 2$ connected pieces $=4$ single pieces

- 3 connected pieces $=6$ single pieces

- $\quad 4$ connected pieces $=8$ single pieces

- 5 connected pieces $=10$ single pieces

Any combination of pieces is acceptable for trade. For example, 5 connected pieces would be worth:

10 single pieces

- 4 connected pieces plus 2 single pieces

- 3 connected pieces plus 2 connected pieces

- 3 connected pieces plus 1 connected piece plus 2 single pieces

- 3 connected pieces plus 4 single pieces

- 2 connected pieces plus 2 connected pieces plus 2 single pieces

- etc.

\section{Directions}

\section{Preparation}

In class, divide the students into at least three groups, and place them in a circle as far away from each other as possible. Have each group choose in which country their firm is located--this is done so that students understand that there are distances among the "firms" that must be crossed in order to do business. Explain that they are now in their "home-country" firms and that the other groups in the room are "foreign" firms in foreign countries.

Mix all of the puzzle pieces from all of the puzzles (including the "extra puzzle") together in one pile. Divide these randomized puzzle pieces evenly among the home-country firms (in the puzzle box bottoms or other containers). Explain that these single pieces are each country's "natural resources" and that once a firm connects any pieces, these connected pieces become manufactured goods inventoried to the firm connecting them.) 
Explain that the goal of the exercise is to complete their chosen puzzle first. (Do not mention the IJV that will be formed in Round 3!) Indicate the puzzle tops or pictures of the completed puzzles that are placed in a neutral location and tell the students to refer to them to complete their puzzles. Explain that there will be three rounds of about 15 minutes each, and that each round will have different rules they must follow on how they may operate. Explain that time will be called and each new set of rules explained before they may proceed, and that before each round they will have 3-5 minutes to plan how to proceed.

\section{Round 1: Entry Phase} the next round.

Explain the rules for Round 1 (answering any questions about them) and then allow 3-5 minutes to plan for

- $\quad$ All assembly takes place at the home country.

- $\quad$ One person at a time from each home country may take one single piece (resource) or one connected group of pieces (a manufactured good) to a "foreign" firm to trade.

- $\quad$ Trades (purchases) are made according to the value-added trade-price schedule (Table I)

- $\quad$ Each person must return home with the purchased raw materials or manufactured goods (puzzle pieces) after every trade.

- When a person returns home, that same person or another person may travel and trade, but only one person may be out of the home country at a time.

- $\quad$ Firms may trade with any other firm, but only one other firm at a time.

- Discussion and alliances with visited foreign firms are allowed, but no general announcements or calls across the room are permitted. (Initially, firms will not know what puzzle each of the other firms is working on, and so must discover this as play progresses.)

Allow the students at least 15 minutes for this round. Most will take some time before they begin to realize that they need pieces from the other groups to complete their puzzles and are ready to start trading.

\section{Round 2: Divisionalization Phase} the next round.

Call time, explain the rules for Round 2 (answering any questions) and then allow 3-5 minutes to plan for

- $\quad$ Assembly takes place at either, or both, the home country and the foreign country.

- $\quad$ One person from each home-country firm--an expatriate--must move to and stay at one of the foreign countries.

- $\quad$ The expats must take puzzle pieces from their home-countries to purchase resources (single pieces) from the foreign country, or manufactured goods (connected pieces) from the foreign firm.

- $\quad$ Expats may purchase and assemble any pieces of their home-country puzzles that they find in the natural resources pile at the foreign location. There are no restriction on the number of pieces for this round.

- Expats may also assemble any other firms' puzzle pieces that they find at the foreign location. By assembling them, they will increase their value for later trade.

- $\quad$ Expats may make occasional (once every 5 minutes) visits back to their home country to take home completed puzzle pieces, and get additional puzzle pieces to buy additional resources at the foreign location.

Allow 10-15 minutes for this round. If the groups should compete all they can at the foreign location, move on to round 3.

\section{Round 3: Globalization Phase} next round.

Call time, explain the rules for Round 3 and answer any questions, then allow 3-5 minutes to plan for the 
- $\quad$ An International Joint Venture (IJV) is formed. Each firm in the room (each a parent firm) must identify one person from its firm to be its representative member in the new IJV firm.

- $\quad$ This IJV attempts to complete its own puzzle (based on the puzzle top picture) with the pieces from the previously "extra" puzzle.

- $\quad$ The IJV solicits donations from each of the parent firms. These would come from any puzzle pieces the firms don't need.

- $\quad$ The IJV competes with the other firms to complete its puzzle first.

- $\quad$ Assembly can be in any country.

- $\quad$ Any employee of any firm can work anywhere.

Allow 10-15 minutes for this round. If one of the groups completes its puzzle, announce that it is the winner. Otherwise, call time after 15 minutes.

\section{Debrief And Discussion}

Play proceeds until one group completes its puzzle and is declared the winner, or time is up for the activity. Process how the students performed on the exercise, asking how each group did and how close to completion each was. Ask what worked and what didn't, what they liked and what not. Then move to the discussion and learning points.

\section{Discussion Questions}

1. In preparing for each round, you were required to plan how to proceed. In effect, you were developing a strategy to internationalize. What strategies did you develop? How were they effective or ineffective? How were the HR issues resolved at each round: How did you select your traders and expatriates? What training, if any, did you give them? Explain any changes you make to your selection and training procedures. How did you evaluate their performance, if you did? What rewards/compensation did you give them for doing their work internationally? If none, why?

2. In round 1 you experienced Entry. Why did you start trading with other firms? What structural form of entry did you use? What other forms of entry are there that firms could use? How did you manage the trade-prices?

3. In round 2 you experienced Divisionalization. What value did divisionalization bring to your firm? Describe the structural form you used. What were some advantages and disadvantages of this over the previous structure? What other forms could a firm use at this stage of development?

4. In round 3 you experienced Internationalization. What value did internationalization bring to your firm over divisionalization? What are some advantages and disadvantages of this form?

5. Also in round 3 you formed an IJV. How successful was that IJV? What could each firm have done to improve its chances? Did any firm abandon its own puzzle to help the IJV to win?

6. In terms of mindset, which of the rounds highlighted ethnocentrism? Which polycentrism? Which geocentrism? Did your mindset change? If so, how did it change?

7. What HR activities might be important at each phase of development?

8. Overall, what did you learn about internationalization from this exercise?

\section{STUDENT EXPERIENCES}

Students have found this to be an interesting and informative exercise. Most say that the exercise brings alive the topics from the book that are difficult to follow and somewhat dry. Most also say that they feel they learned more from the exercise than from reading the descriptions in the book, that actually engaging in an exercise to simulate the internationalization experience gave them a greater appreciation for the need for structure, forms and mindsets. The students who were not able to complete the puzzle in the allotted time were frustrated with that aspect and wanted to continue working on the puzzle, but still found it to be an exciting exercise. 


\section{CONCLUSION}

In sum, this exercise is an enjoyable, effective method to teach students about the importance of strategic choices that need to made at different points in the internationalization process. The students begin to understand that to be competitive in the global economy, firms need to expand their thinking and facilities beyond the domestic marketplace or suppliers. They discover that at some point, most companies will find a need to develop synergies and relationships with firms in other countries, in order to gain the resources (their missing puzzle pieces) or a new marketplace to "sell" their unneeded or excess inventory (the puzzle pieces that they don't need). More importantly, they realize that international trade can be a win-win situation where all parties are able to find a fit for their efficiencies and their needs. They see that companies tend to develop knowledge and confidence in one phase before they move on to a more complex phase in international trade. They also acquire an understanding of the different structural forms that are incorporated into a global strategy. Further, they have a chance to implement the concept of value-added, and experience a few of the complexities involved in trading at a distance. The exercise and discussion also highlight the concepts of global mind-sets and HR activities necessary in each phase of internationalization.

\section{REFERENCES}

1. Blanton, K.K. \& Barbuto, J.E. Jr. (2005). Cultural constraints in the workplace: An experiential exercise utilizing Hofstede's dimensions. Journal of Management Education, 29(4), 654-666.

2. Bradford. (2007). Training for success in emerging markets: Innovative HR a key to unlocking Far East success. Strategic Direction 23(9), 36-38.

3. Briscoe, D. \& Schuler, R. (2004) International human resource management, ( $2^{\text {nd }}$ ed.). London and New York: Routledge.

4. Burgi, P., Victor, B., \& Lentz, J. (2004). Case study: Modeling how their business really works prepares managers for sudden change. Strategy \& Leadership, 32(2), 28-35.

5. Harvey, C. \& Morouney, K. (1998). Organization structure and design: The Club Ed exercise. Journal of Management Education; 22(3), 425-429.

6. Joshi, M., Davis, E., Kathuria, R. \& Weidner, C.K. (2005). Experiential learning process: Exploring teaching and learning of strategic management framework through the winter survival exercise. Journal of Management Education, 29(5), 672-695.

7. Ledman, R.E. (2001). The family impact of expatriate assignments: An experimental exercise. Journal of Management Education, 25(3), 341-

8. Lyons, P. \& Nicol, D. (2001). Structuring-by-the-numbers: A process for discovering and understanding organizational structure. Journal of Management Education, 25(6), 726-736.

9. Miller, L.E. (2007). Teaching technology-structure contingencies by "Harnessing the Wind." Journal of Management Education, 31(4), 555-571.

10. McDonald, D.M.(2001). International exchange game: A hidden social dilemma. Journal of Management Education, 25 (4), 425-429.

11. Murphy, T.E. (2002). Market forces and the Middle East's new interest in HRM. Business Horizons, 45(5), 63-71.

12. Oddou, G.R. (2005). A cross-cultural exercise: Expat in the marketplace. Journal of Management Education, 29(5), 758-768.

13. Punnett, B.J. (2005). Experiencing international business and management: Exercises, projects, and cases. Armonk, NY: M.E. Sharpe Inc. 